\title{
Plans for Constructing a Next-generation ISOL Facility at ORNL
}

\author{
J. D. Garrett,* G. D.Alton,* R. L. Auble,* C. Baktash,* J. R. BOņ* \\ F. E. Bertrand, ${ }^{*}$ J. D. Fox,* R. A. Gough, ${ }^{\dagger}$ M. L. Halbert,*
} J. G. Kalnins, ${ }^{\dagger}$ Y. Liu, ${ }^{*}$ M. W. Ogan, ${ }^{\#}$ F. Plasil, ${ }^{*}$ D. Shapira, ${ }^{*}$ P. T. Spampinato, J. W. Staples, ${ }^{\dagger}$ H. Wollnik, ${ }^{\ddagger}$ and M. S. Zisman ${ }^{\dagger}$

\author{
* Physics Division, Oak Ridge National Laboratory, Oak Ridge, Tennessee, 37831 \\ ${ }^{\dagger}$ Accelerator and Fusion Research Division, Lawrence Berkeley National Laboratory, \\ * Berkeley, California 94720 \\ \# Engineering Division, Oak Ridge National Laboratory, Oak Ridge, Tennessee, 37831 \\ Robotics and Process Systems Division, Oak Ridge National Laboratory, \\ Oak Ridge, Tennessee, 37831 \\ $¥$ University of Giessen, Giessen D-6300, Germany
}

\begin{abstract}
The U.S. Nuclear Science Community in its 1996 Long Range Plan identified an advanced radioactive ion beam (RIB) facility based on the ISOL technique as the next major facility to be constructed for U.S. nuclear physics. The proposed Spallation Neutron Source (SNS) for Oak Ridge National Laboratory, whose construction design funds have recently been appropriated, offers a unique opportunity for the construction of this new facility. Plans for extracting a proton beam from the SNS, transporting it to the RIB facility, and constructing the new RIB facility at the SNS site are discussed, as are the ISOL targets, radiation handling, isobaric separation, acceleration of beams of radioactive ions, and the layout of the experimental areas.
\end{abstract}

\section{BACKGROUND}

The Nuclear Science Advisory Committee (NSAC), an official DOE/NSF advisory body, has identified an Isotope-Separator-On-Line (ISOL) Radioactive Ion Beam (RIB) Facility in its 1996 Long Range Plan for U.S. Nuclear Science as the next major facility to be constructed under the auspices of DOE's Nuclear Physics Program Office. The Long Range Plan states: "The scientific opportunities made available by world-class radioactive beams are extremely compelling and merit very high priority. The U.S. is well-positioned for a leadership role in this important area. ... We strongly recommend development of a cost-effective plan for a next generation ISOL-type facility and its construction when current major construction activities are substantially complete."

The on-line isotope-separator technology (1), developed at CERN and at other facilities, has progressed to the extent that it is feasible to produce and accelerate beams of short-lived isotopes with sufficient intensity to address a large variety of new nuclear structure, nuclear astrophysics, and materials science problems (2-6). Several firstgeneration ISOL facilities, e.g., the Holifield Radioactive Ion Beam Facility (7) (HRIBF) at ORNL, are being constructed or are in operation in North America, Europe, and Japan, based on existing accelerators and reactors.

\footnotetext{
The submitted manuscript has been

authored by a contractor of the U.S.

AC05-960R22464. Accordingly, the U.S.

Government retains a nonexclusive,

royalty-free icense to pubish or reproduce,

the published form of this contribution $\alpha$

alow others to ch so, for U.S. Govemment

purposes."
} 


\section{DISCLAIMER}

This report was prepared as an account of work sponsored by an agency of the United States Government. Neither the United States Government nor any agency thereof, nor any of their employees, make any warranty, express or implied, or assumes any legal liability or responsibility for the accuracy, completeness, or usefulness of any information, apparatus, product, or process disclosed, or represents that its use would not infringe privately owned rights. Reference herein to any specific commercial product, process, or service by trade name, trademark, manufacturer, or otherwise does not necessarily constitute or imply its endorsement, recommendation, or favoring by the United States Government or any agency thereof. The views and opinions of authors expressed herein do not necessarily state or reflect those of the United States Government or any agency thereof. 


\section{DISCLAIMER}

Portions of this document may be illegible in electronic image products. Images are produced from the best available original document. 
A Workshop on the Science for an Advanced ISOL Facility, organized jointly by ORNL and ANL, was held at Ohio State University in Columbus, Ohio, July 30 -August 1, 1997. The scientific case developed at this workshop was summarized in a White Paper (6), which was submitted to the Nuclear Physics Program Office at DOE in November 1997. This White Paper has been used as the basis of a "Mission Need" document which has been prepared by the Nuclear Physics Program Office at DOE. Current DOE plans calls for starting the construction of this Next-generation ISOL Facility (NISOL) after the peak of the Spallation Neutron Source (SNS) construction budget which is projected to be reached in FY 2002.

The proposed NISOL Facility must provide the large variety of very intense radioactive ion beams necessary to take full advantage of the scientific opportunities afforded by this new interdisciplinary research tool. Indeed, in 1990 a North American Steering Committee for Radioactive Ion Beam Physics was established. After canvassing the nuclear physics and nuclear astrophysics communities, this committee proposed (2) an advanced ISOL facility in 1991, in which the radioactive atoms were produced using $1-\mathrm{GeV}$ protons. Due to the cost of constructing a $1-\mathrm{GeV}$ proton accelerator (estimated to be in excess of $\$ 400$ million for the SNS more recent considerations (8) of the NISOL Facility have been based on $200-250 \mathrm{MeV}$ accelerated protons and deuterons. However, the recent funding of the SNS (9) with its beam of 1$\mathrm{GeV}$ protons provides the unique opportunity to utilize the advantages of higher-energy protons for producing radioactive ions. The higher-proton energy spreads the energy loss through a thicker target. Thus, for the same power dissipated in a given target, the $1-\mathrm{GeV}$ proton beam will produce a smaller density of energy deposited per unit volume than a less energetic proton or heavier-ion beam. The higher-energy proton beam will also provide a greatly increased production yield of both neutron-rich fission products and predominately proton-rich spallation products. Siting the NISOL Facility at the SNS will provide a "green field" for the remainder of the facility in which the RIB accelerator and experimental equipment can be optimized with the money saved by using proton beams from the SNS linac to produce the radionuclides. Likewise, other cost efficiencies, e.g., in facility operation and ESH, are being investigated. Construction at the SNS site will also minimize the impact on the HRIBF operation during the construction. During this period the HRIBF will be the only ISOL facility in the U.S., and its technical and scientific program will be crucial in defining the early program for the NISOL Facility.

\section{SCIENTIFIC MOTIVATION}

A description of the multidisciplinary scientific topics that a NISOL Facility can address is documented in a number of reports (2-8). The most recent such document, the OSU Symposium White Paper (6) provided to the U.S. DOE in November 1997, is being used to justify the construction of a NISOL Facility. Such a facility will afford research opportunities to a variety of scientific disciplines as diverse as nuclear structure physics, astrophysics, standard model tests, materials science, tribology, and biological and medical sciences. Siting the NISOL Facility together with the SNS would provide radioactive ions for materials science and biological studies at the same location as the premier neutron scattering facility. 


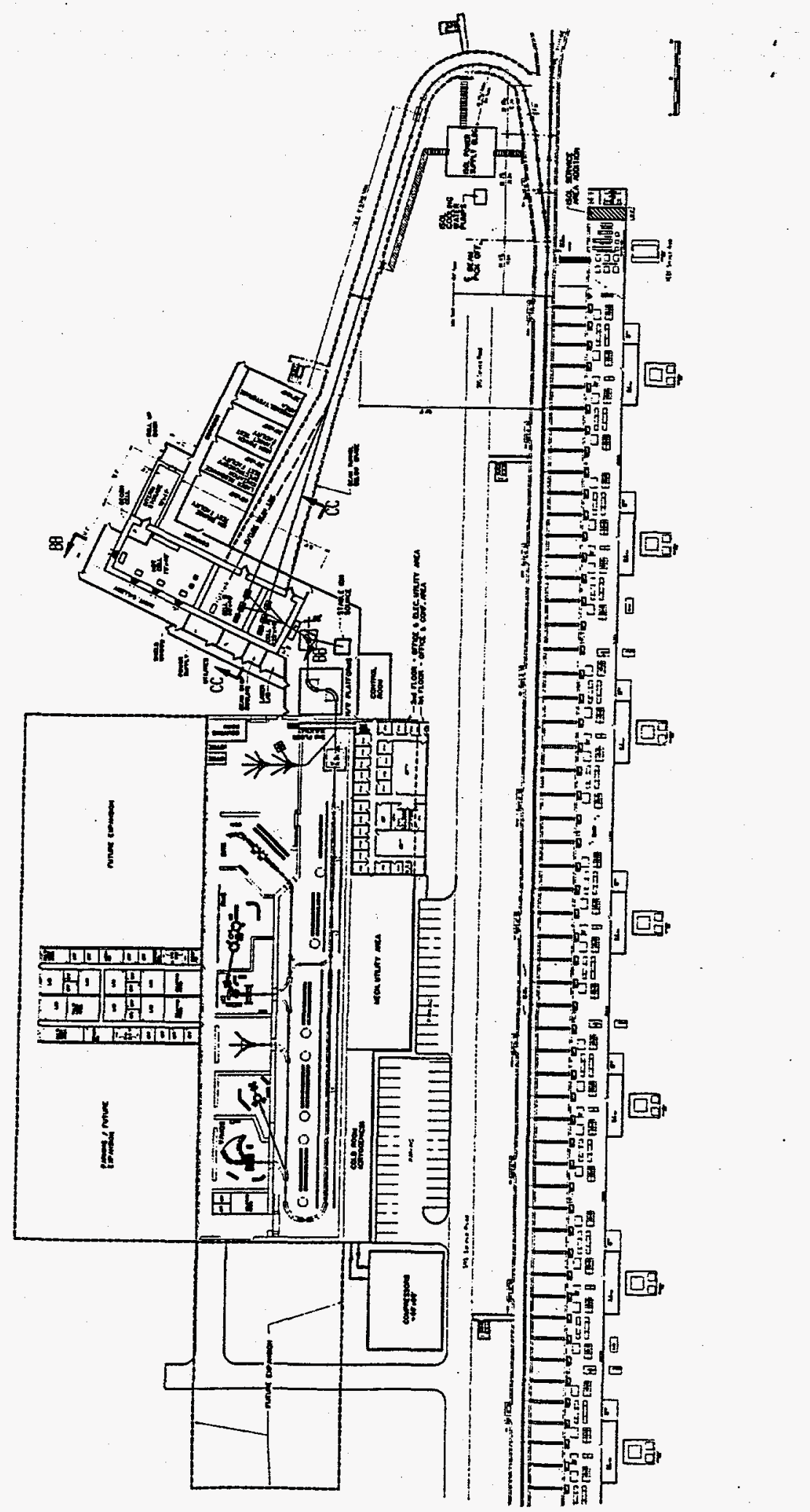

FIGURE 1. Preliminary schematic diagram of the planned NISOL Facility at the SNS site at ORNL. Enlarged diagrams of the target, ion source, and radiation areas and the accelerator and experimental areas of this planned facility are shown in Figures 4 and 9, respectively. 
The NISOL facility proposed for the SNS site at ORNL will be capable of providing a broad range of intense proton- and neutron-rich beams of radioactive ions to a large scientific user community. The new facility will produce intense' beams of many neutron- and proton-rich isotopes whose halflives are greater than about one second and that are sufficiently volatile to diffuse out of a heated target. Both protonand neutron-rich RIBs will be accelerated from tens of $\mathrm{keV}$, for materials- and biological-science studies, nuclear mass measurements, and radioactive target preparation, to energies near and above the Coulomb barrier for nuclear structure, nuclear reaction, and nuclear astrophysics studies.

\section{THE NISOL FACILITY AT THE SNS}

The general layout of the NISOL Facility which could be constructed at the SNS Site is shown in Figure 1 and an artistic conception of what this facility might look like is shown in Figure 2. A time-averaged beam intensity of about $100 \mu \mathrm{A}$, i.e., $10 \%$ of the SNS's initial designed beam intensity, would be added to the SNS $\mathrm{H}^{-}$beam. This added intensity would be extracted in the High Energy Beam Transport (HEBT) line downstream from the end of the SNS $\mathrm{H}^{-}$linac and provided to the NISOL facility. The extraction will be accomplished by deflecting the $\mathrm{H}^{-}$beam by about $2.5^{\circ}$ as shown in Figure 3. After deflection a thin foil (or perhaps a wire or a grid) would be inserted in the edge of the $\mathrm{H}^{-}$beam to strip the desired portion of the $\mathrm{H}^{-}$beam to $\mathrm{H}^{+}$, i.e., to protons. The proton beam will be separated from the $\mathrm{H}^{-}$beam in a separator magnet. Then it will be transported to the NISOL facility through a high-energy proton transport line, see Figure 1. The unstripped $\mathrm{H}^{-}$beam ( $>90 \%$ of the total beam) will be deflected in the opposite direction from the proton beam in the separator magnet and returned to the HEBT by another small magnet. Preliminary calculations indicate that these three magnets should have fields below about 0.3 Tesla. The intensity of the stripped proton beam can be varied by moving the foil; fine tuning can be accomplished by "tweaking" the deflection magnet upstream of the stripper. Stripping only a limited area of the $\mathrm{H}^{-}$ beam ensures that the emittance of the extracted proton beam will be comparable to or less than that provided to the SNS. Using a relatively thick stripper foil $\left(\approx 1 \mathrm{mg} / \mathrm{cm}^{2}\right)$ minimizes the production of $\mathrm{H}^{\circ}$ atoms. Nevertheless, it will be necessary to provide a low-intensity $\left(<10\right.$ Watts of $\left.1 \mathrm{GeV} \mathrm{H}^{\circ}\right)$ beam stop to safely dispose of this small fraction of the $\mathrm{H}^{\circ}$ beam that remains as $\mathrm{H}^{\circ}$ after the stripping.

The proton beam will enter the NISOL facility on the lower level where all the target stations and the other high radiation areas will be located. Two sets of two closely spaced target stations are indicated in Figures 4, 5 and 6. Options for operating the two stations on a specific beam line by allowing the proton beam to simultaneously transverse both targets or by time sharing the beam between these two targets are being investigated. An additional target area to the right of the two shown also is being reserved for future developments.

The ion sources would be located above, but perhaps offset, from the target. This slight offset would reduce the line of sight radiation from the target up the beam line. The ionized beams would be focused upward through a series of separated vacuum envelopes to a low-resolution $(\Delta \mathrm{m} / \mathrm{m}=1 / 500)$ preseparator which would bend the beam into the horizontal plane (see Figure 7). The low-resolution separator would remove the radioactive ions with masses other than that of the isotope of interest thereby reducing the radioactivity deposited in the remaining separators and beam-handling devices. It might be possible to recover a portion of these radionuclides for use as targets or other purposes. All of the services to the target and ion source and the associated vacuum enclosures (electrical, cooling water, control, $\mathrm{He}$, laser channel, etc.) would be provided through the vertical tube. The vacuum to be provided by 


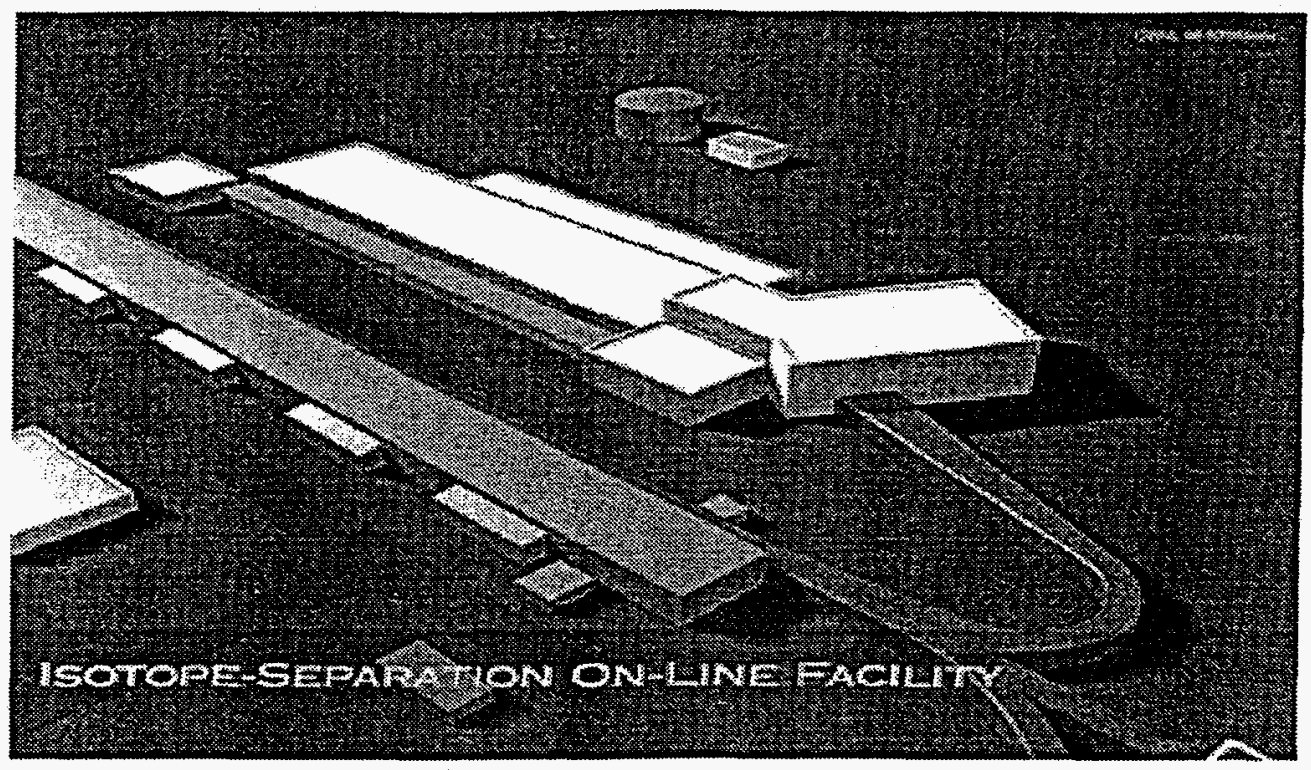

FIGURE 2. Artist's conception of the planned NISOL Facility at the SNS site at ORNL.

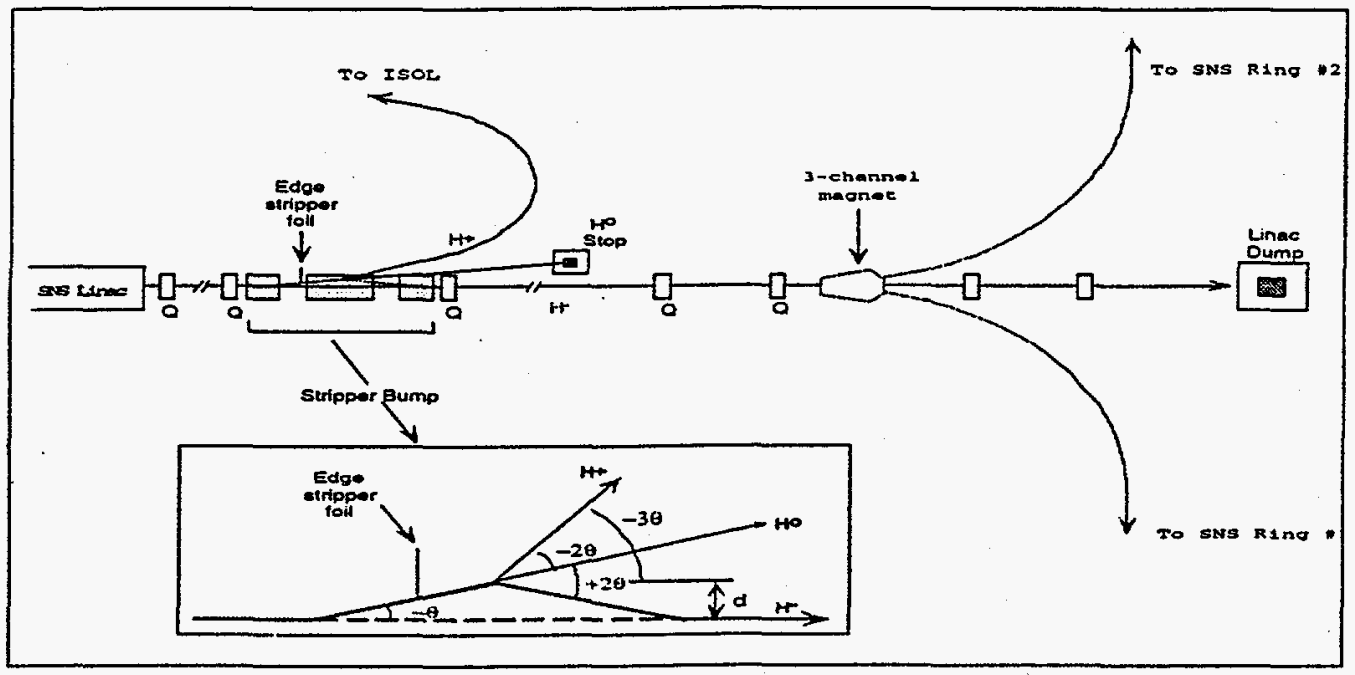

FIGURE 3. Schematic diagram illustrating the technique for extracting up to $\approx 10 \%$ of the $\mathrm{H}^{-}$beam after the SNS linac, converting it to protons by stripping, and providing it to the NISOL site while returning the remainder of the beam to the HEBT of the SNS.

cryopanels should be sufficient for ion source operation $\left(\approx 10^{-6}\right.$ Torr $)$. The three separated vacuum envelopes of the vertical tube and preseparator are designed to maximize the localization of the radioactivity in the lower portions of this assembly. The whole target ion source assembly together with the three-stage vacuum envelopes (and perhaps the low-resolution separator magnet) would be removed as a unit for service. This assembly would be removed vertically by a crane which would insert it into shielded hot cells for servicing the target and ion source assemblies--See Figure 6. Target and ion source assembly, servicing, testing, and used target storage areas would be located near the RIB production target areas as indicated in Figure 4. 


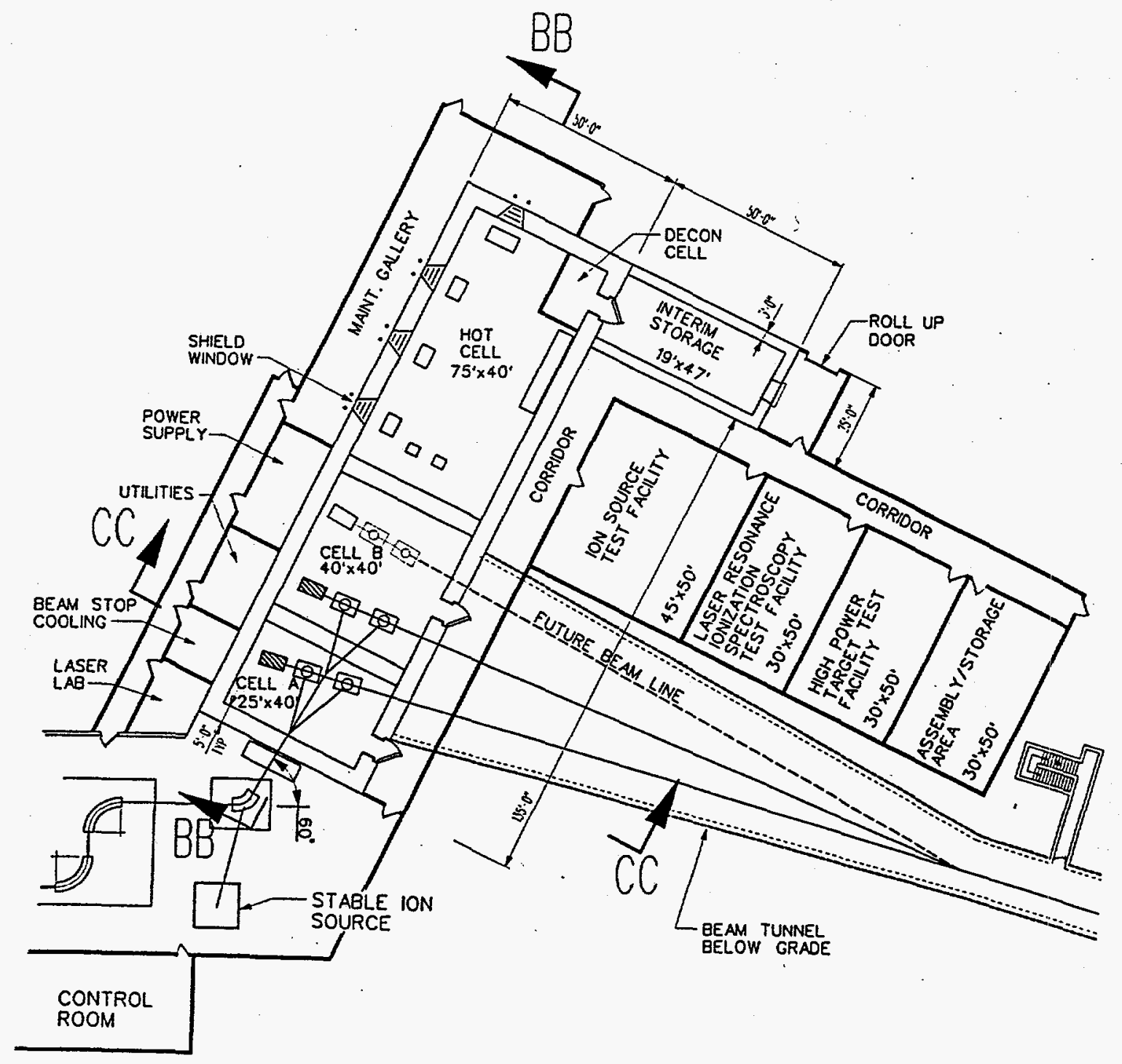

FIGURE 4. Expanded portion of Figure 1 showing the target, ion source, radiation handling, and hot cell areas for the planned NISOL facility at the SNS site. 


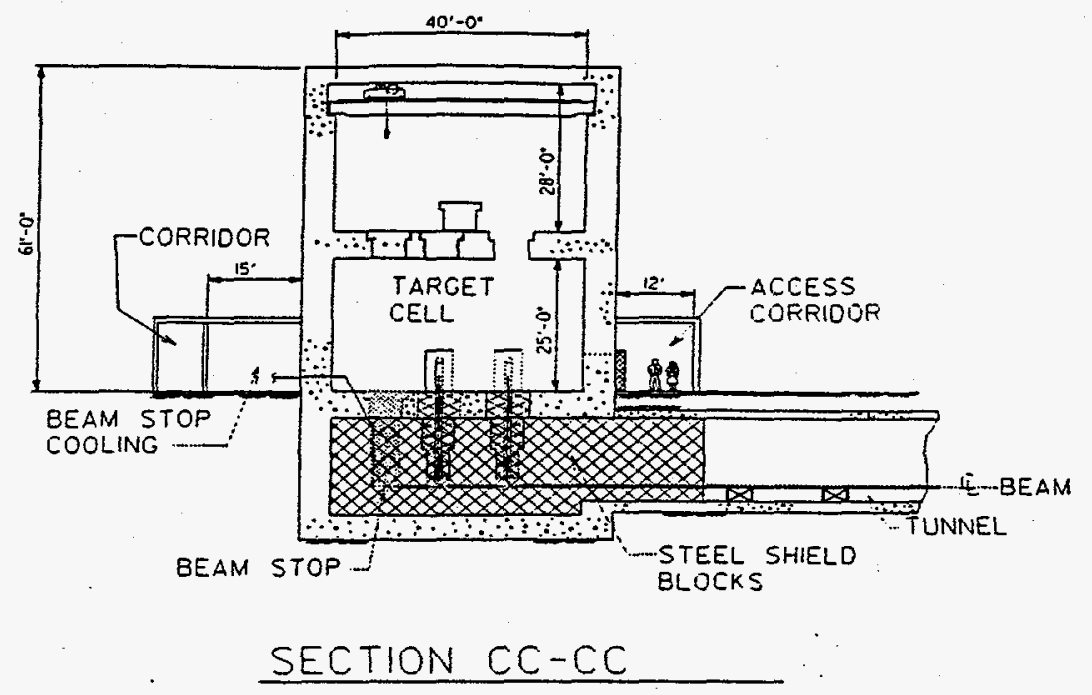

FIGURE 5. Cross-sectional side view along the beam direction of the proton beam line showing the target and beam stop areas, see Figure 4.

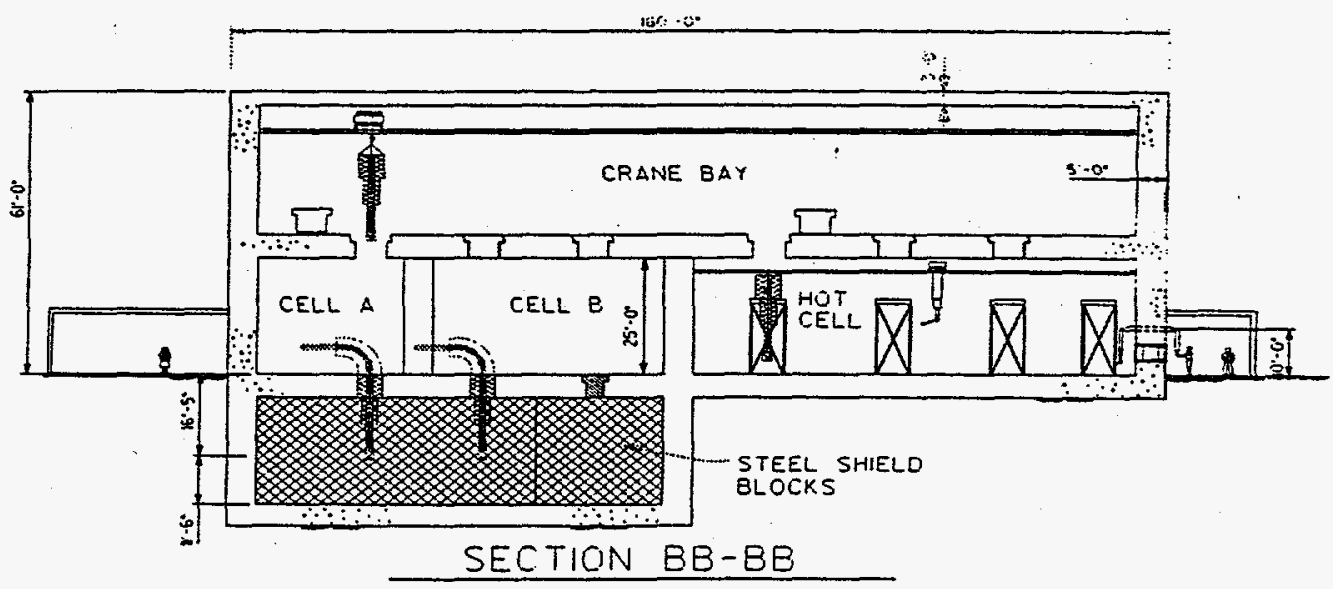

FIGURE 6. Cross-sectional side view perpendicular to the beam line showing a target area, the radiation handling, and the hot cell areas, see Figure 4. Note a target ion source assembly in transit (in the crane bay) between target cell A. Likewise, similar assemblies are shown in the target positions and being serviced in the hot cell. An expanded view of the target ion source assembly is shown in Figure 7. 


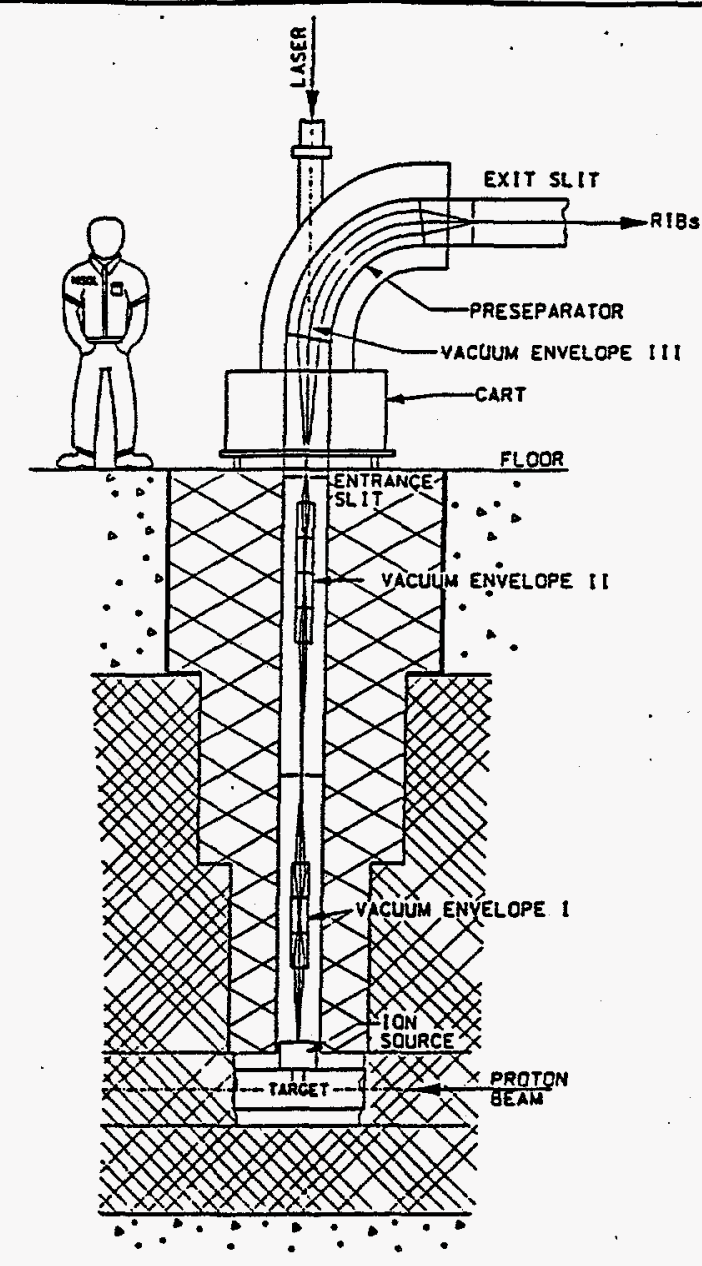

FIGURE 7. Expanded view of the target, ion source, vertical beam transport, and preseparator showing the three-stage vacuum envelopes maximizing radiation containment in the shielded areas. This assembly would be remotely removed vertically and serviced in the hot cell shown in Figures 4 and 6.

Ion sources under consideration for the NISOL facility include electron cyclotron resonance (ECR), electron beam plasma (EBP) (i.e., modifications of the sources used for ISOLDE (1) and the HRIBF (7), and laser sources. A stable ion source for providing test beams of stable ions also is shown in Figures 1 and 4.

A three-stage isobar separation system with a resolution of $\Delta \mathrm{m} / \mathrm{m} \approx 1 / 20,000$ is shown in Figures 1 and 4 . The low-resolution vertical-to-horizontal bending preseparator (described above) is the first stage of this system. The second and third stages are an improved version of the present HRIBF isobaric analysis system (7) with a single-magnet second stage $(\Delta \mathrm{m} / \mathrm{m} \approx 1 / 2500)$ and a double-bend third stage $(\Delta \mathrm{m} / \mathrm{m} \approx$ $1 / 20,000$ ). To provide maximum flexibility for a wide variety of masses and charge states, all these magnets will be at high voltage as will the RFQs. Space will be reserved before the second stage isobaric analyzer for the installation of a beam cooler. Likewise space also will be reserved between the isobaric analyzer and the RFQ for the future installation of a charge state enforcer, e.g., an electron beam ion trap (10) (EBIT), if this technology proves to be useful. 


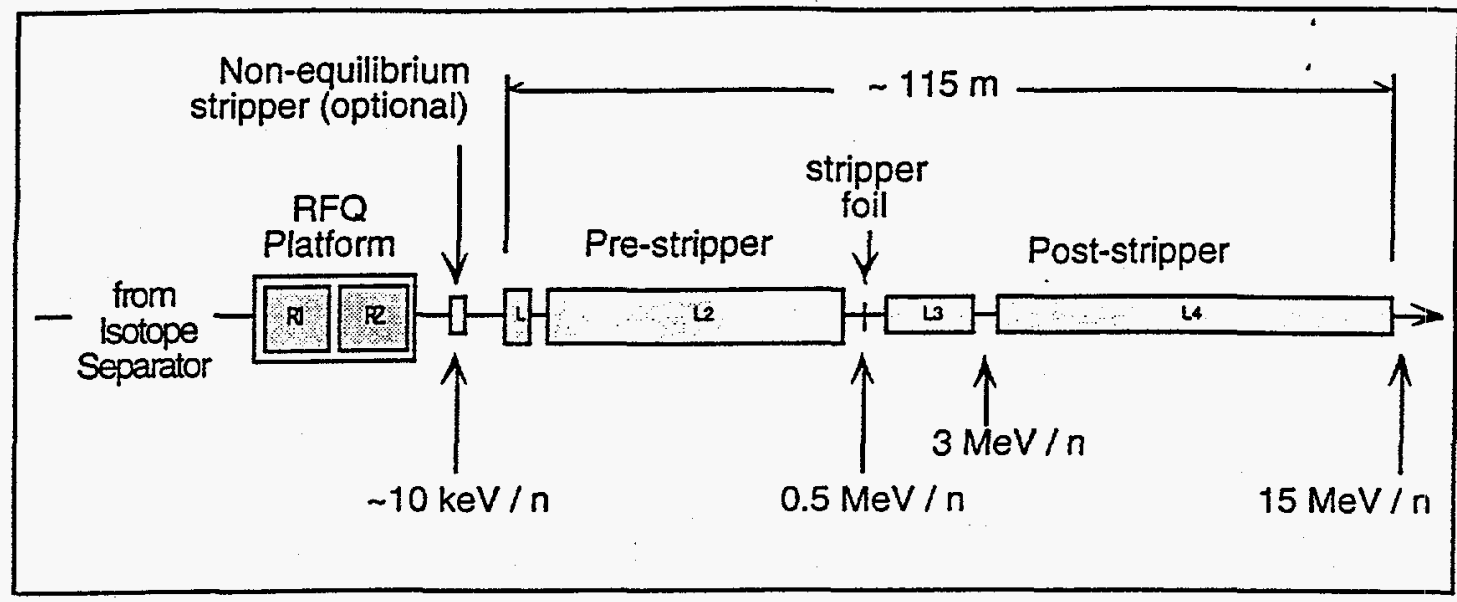

FIGURE 8. Schematic diagram of a possible layout of the RFQs and the superconducting linac for the NiSOL facility.

A layout for a two-stage RFQ and a four-stage superconducting heavy ion linac, capable of accelerating single-charged ions of $A \approx 140$ to $15 \mathrm{MeV} / \mathrm{u}$ is shown in Figures 1,8 and 9 . In this scheme the heavy ions would be stripped to an equilibrium charge state after the first two stages of the heavy-ion linac. The heaviest ions (i.e., masses greater than about 140) would be extracted as $q=2$ from the ion source or stripped to $q=2$ after the first RFQ stage. The RFQ will probably be of the split coaxial type (SCRFQ) now operating (11) at the KEK/Tanashi Facility (previously the Institute of Nuclear Studies of the University of Tokyo) in Tokyo. To achieve the very low $\mathrm{g} / \mathrm{m}$ values $(\approx 1 / 140)$ the SCRFQ would operate at about $12.5 \mathrm{MHz}$.

A large, versatile experimental area, allowing a nearly continuous range of beam energies (from $\approx 100 \mathrm{keV}$ to $15 \mathrm{MeV} / \mathrm{u}$ ) to be directed to a variety of experimental apparatus, is shown in Figures 1 and 9. From left to right the experimental apparatus shown for illustrating the size and the versatility of this area are:

- A highly efficient mass separator (e.g., VAMOS proposed for GANIL);

- a versatile time-of-flight setup for nuclear reactions studies;

- a series of general purpose beam lines for customized small experimental setups;

- the present HRIBF Recoil Mass Separator (RMS) with a large germanium array (e.g., GRETA) at the target position and a battery of focal-plane detectors;

- an upgraded version of the Daresbury Recoil Separator (DRS) optimized for astrophysics experiments; and

- an "unaccelerated" beam area including mass traps and other apparatus for materials science and biomedical studies with unaccelerated beams.

For more information on the experimental equipment applicable to the NISOL Facility the reader is referred to the proceedings of a recent workshop on this topic (12).

To take advantage of the "green field" approach available at the SNS site the area at the high-energy end of the heavy-ion linac is reserved for future upgrades as are areas adjacent to the experimental hall. Likewise additional space is provided for an upgraded RIB target station, since targets and ion sources are considered to be the area that future technical breakthroughs are most likely to occur. 


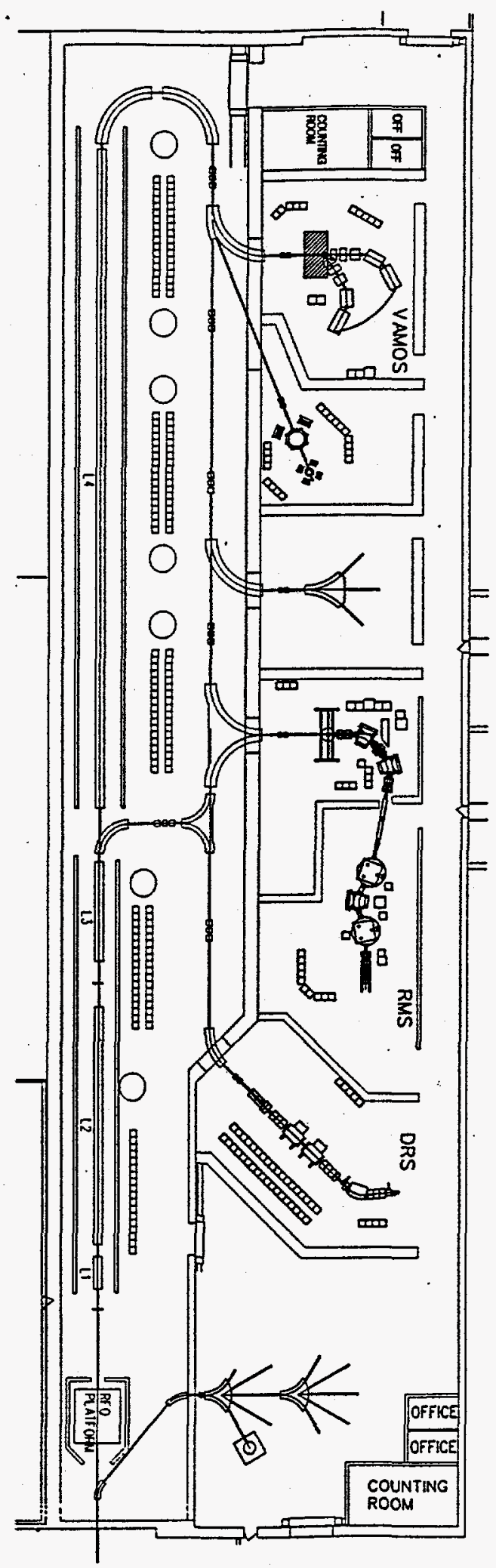

FIGURE 9. Expanded portion of Figure 1 showing RFQs and a superconducting linac capable of accelerating $q=1$ ions of $A=140$ to $15 \mathrm{MeV} / \mathrm{u}$. A layout of a variety of experimental equipment described in the text also is shown to illustrate the dimensions of the experimental area. 


\section{ACKNOWLEDGMENTS}

The authors acknowledge many informative discussions with Jose Alonso and other members of the SNS technical staff. This research is sponsored by the Laboratory Directed Research and Development Program of Oak Ridge National Laboratory, managed by Lockheed Martin Energy Research Corp. for the U.S. Department of Energy under contract DE-AC05-96-OR22464. The LBNL portions of this work also were partially supported by the U.S. Department of Energy under contract No. DEAC03-76SF 00098.

\section{REFERENCES}

1. Ravn, H. L. and Allardyce, B. W, "On-Line Mass Separators," Treatise on Heavy Ion Science, ed. Bromley, D.A. (Plenum Press, 1989, New York, Vol. 8, pg. 363).

2. Casten, R. F., D'Auria, J. M., Davids, C. N., Garrett, J. D., Nitschke, J. M., Sherrill, B. M., Vieira, D. J., Wiescher, M. and Zganjar, E. F., "The Iso-Spin Laboratory: Research Opportunities with Radioactive Nuclear Beams," Los Alamos National Laboratory Report LALP91-51.

3. Casten, R. F., D'Auria, J. M., Davids, C. N., Garrett, J. D., Nitschke, J. M., Sherrill, B. M., Vieira, D. J., Wiescher, M. and Zganjar, E. F., "Overview of Research Opportunities with Radioactive Nuclear Beams," February 1995, available from R. F. Casten, Yale University.

4. "European Radioactive Beam Facilities," NuPECC Report, May 1993.

5. Tanihata, I., "RI Beam Project," Nucl. Phys. A616, pp. 56c-68c (1997) and "RI Beam Factory: Basic Science," RIKEN Accelerator Research Facility Report, August 1994.

6. Casten, R.F. et al., "Scientific Opportunities with an Advanced ISOL Facility," OSU Symposium White Paper, November 1997, available from J.D. Garrett, ORNL, or from the NISOL website (http://www.phy.ornl.gov/nisol.html).

7. Garrett, J. D., Nuclear Physics A616, pp. 3c-10c (1997) and references therein.

8. Rehm, K. E. et al., "Concept for an Advanced Exotic Beam Facility based on ATLAS," Physics Division Annual Report, Argonne National Laboratory, April 1, 1994-March 31. 1995, ANL-95/14, p. 56.

9. "The Spallation Neutron Source Conceptual Design Report,http://www.ornl.gov/ nsns/CDRDocuments/CDR.html.

10. EBIT, Marts, R. E. et al., Phys. Rev. Lett. 60, 1715 (1988); and Levine, M. A. et al., Phys. Scr. T22, 157 (1988).

11. Arai, S. et al., Nuclear Instruments and Methods A390 (1997) pp. 9-24.

12. Proceedings of the Workshop on the Experimental Equipment for an Advanced ISOL Facility, edited by I. Y. Lee, Nuclear Science Division, Lawrence Berkeley National Laborator, July 22-25, 1998. 